\title{
Teenage health scientists honoured
}

A 16-year-old Calgary, Alberta student recently earned first place nationwide in the annual Sanofi BioGENEius Challenge Canada, a biotechnology research competition that encourages high school students to pursue future studies and careers in life sciences.

Arjun Nair, a grade 11 student at Calgary's Webber Academy, conducted research into an experimental cancer treatment that involves injecting patients with nanoparticles of gold. The particles accumulate in tumours, forming so-called "nanobullets" that can be heated to kill cancer cells.

Nair won \$8500, including a special $\$ 1000$ prize for the research project the judges deemed as having the greatest commercial potential.

"There were so many amazing projects, I never expected to win, so it was quite a shock and surprise," says Nair. His mentors are Drs. David Thomas Cramb and Simon Trudel, both in the University of Calgary's Department of Chemistry. Last year, after learning of Nair's theoretical research, they invited him to conduct experiments in their laboratory.

"My learning curve in that lab was exponential," Nair says. "It's really exciting to be part of the scientific community and to look at unique ideas that could potentially save lives down the road." With high school graduation a year away, Nair has set his sights on a career as a research physician. "To be a practising doctor and continue to conduct research - for me, that will be the best of both worlds," he says.

Second place in the competition went to Selin Jessa, 17, a Coquitlam, British Columbia grade 12 student who

compromise its ability to replicate. Identifying these viral mutations may help design vaccines or other HIV therapies.

According to Jessa's mentor, Dr. Zabrina Brumme, assistant professor at Simon Fraser University in Vancounver, $\mathrm{BC}$, Jessa was doing university graduatelevel research. Only two dozen researchers worldwide are researching mutations in elite controllers and engineering them in vitro.

Jessa said she was honoured to have been among the winners. "Doing hands-on research this year was a transformative experience, and the competition has definitely catalyzed my direction for university and beyond. What I've learned is that science is as much about being intensely curious about the world as it is about exploring ways to make it better, and I hope to keep doing both as long as I can."

Jessa won $\$ 7500$ in prize money from her

presented a project on HIV proteins. Jessa's project involved the engineering of a mutant version of an HIV protein, allowing her to learn and apply various techniques in molecular biology including molecular cloning, DNA sequencing, cell culture and flow cytometry.

A rare few patients infected with HIV are known as "elite controllers," individuals whose immune systems naturally control common symptoms of the virus. The immune responses of elite controllers are so effective that HIV can only survive through mutations that placements at the regional, national and international competitions.

Canadians have featured among the top international prize winners in the BioGENEius Challenge over the past few years. In 2012, Rui Song from Saskatoon, Saskatchewan, took third prize; in 2007, Ted Paranjothy of Winnipeg, Manitoba took first place; and in 2003, Anila Madiraju of Montréal, Quebec came home with third prize. Lauren Kramer, Vancouver, BC

CMAJ 2013. DOI:10.1503/cmaj.109-4505 